\title{
AGROINDÚSTRIA CANAVIEIRA E DESENVOLVIMENTO LOCAL: O CASO DA USINA USACIGA NO MUNICÍPIO DE CIDADE GAÚCHA-PR ${ }^{1}$
}

\author{
Pery Francisco Assis Shikida ${ }^{2}$ \\ Elvanio Costa de Souza \\ Vanessa de Souza Dahmer
}

Resumo - Este trabalho objetivou estimar o emprego básico e seu efeito multiplicador sobre o emprego total no município de Cidade Gaúcha-PR, ressaltando a contribuição da Usina Usaciga. Como resultado, 1.739 pessoas compõem o setor básico do município, enquanto 1.176 pessoas fazem parte do setor não-básico. A Usina Usaciga é responsável por $39,7 \%$ do emprego básico de Cidade Gaúcha, cuja dinâmica do crescimento populacional se modificou a partir da década de 80, período de início das atividades da Usaciga. Concomitante, houve evolução favorável, no que concerne ao Índice de Desenvolvimento Humano (IDH), neste município.

Palavras-chave: agroindústria canavieira, desenvolvimento local, multiplicador de emprego.

Recebido em: 14/01/08 Aceito em: 03/03/08

Este trabalho contou com o apoio da Fundação Araucária (PR)

2 Professor Associado da Universidade Estadual do Oeste do Paraná (UNIOESTE). Bolsista de Produtividade em Pesquisa do CNPq e Pesquisador do GEPEC. E-mail: pfashiki@unioeste.br

3 Economista pela UNIOESTE-Toledo. Mestrando em Economia Aplicada pela Universidade Federal de Viçosa (UFV). E-mail: elvaniosouza@yahoo.com.br

4 Acadêmica do Curso de Ciências Econômicas e Bolsista do Programa PIBIC-CNPq-UNIOESTE.

E-mail: vanedahmer@unioeste.br 


\section{Introdução}

A idéia da intensificação do cultivo da cana-de-açúcar no Paraná surgiu diante da busca de uma alternativa agrícola que substituísse as lavouras decadentes do café no norte do Estado e, ao mesmo tempo, gerasse trabalho para as famílias desempregadas na agricultura (Guerra, 1995). Desse modo, a crise da cafeicultura (1965-67) permitiu um "transbordamento" da agroindústria canavieira, já difundida em São Paulo, para regiões circunvizinhas, com destaque para Minas Gerais e Paraná (Kaefer e Shikida, 2000).

Entretanto, o avanço mais expressivo da agroindústria canavieira paranaense só ocorreu a partir da segunda fase do Programa Nacional do Álcool (Proálcool), que se iniciou após o advento do $2^{\circ}$ choque do petróleo, em 1979. Este, aliado à alta das taxas de juros internacionais, levou o governo brasileiro a acelerar a implementação do uso de álcool hidratado como combustível, estimulando a implantação de destilarias autônomas, tanto em regiões tradicionais - Estados do Sudeste e Nordeste do País - como em novas regiões produtoras, como Paraná, Goiás, Mato Grosso e Mato Grosso do Sul (Shikida, 1998).

Atualmente, o Paraná conta com 27 unidades produtoras, sendo 18 usinas com destilarias anexas e 9 destilarias autônomas ${ }^{5}$ [Associação de Produtores de Álcool e Açúcar do Estado do Paraná - ALCOPAR, 2007]. As empresas da agroindústria canavieira paranaense atingem economicamente 126 municípios, gerando aproximadamente 74 mil empregos diretos.

Segundo Macedo (2007), a geração de empregos (agrícolas e industriais) tem sido um dos pontos mais fortes da indústria da cana, visto que ajuda a tolher a migração para as áreas urbanas e a melhorar a qualidade de vida em muitas localidades. Nos 357 municípios brasileiros com destilarias

Usinas com destilarias anexas são aquelas que produzem tanto açúcar quanto álcool, enquanto destilarias autônomas produzem apenas álcool. 
de álcool, estas proporcionam 15 a $28 \%$ do total de empregos. Segundo este autor, avalia-se em cerca de 610 mil os empregos diretos e $930 \mathrm{mil}$ os indiretos e gerados pela agroindústria canavieira no Brasil.

Mediante compras de equipamentos/insumos e contratação de serviços por parte das usinas de açúcar e álcool, mais de 50 mil empresas são beneficiadas. Em unidades monetárias, o volume de investimento ultrapassa R $\$ 4$ bilhões/ano. A geração de impostos é outro indicador da importância social do agronegócio canavieiro, já que são recolhidos, a cada ano, mais de R $\$ 12$ bilhões aos cofres públicos (Silva e Pontili, 2005).

Não só de pontos positivos vive o setor agroindustrial canavieiro. Cumpre destacar os prejuízos ambientais e à saúde pública ocasionados pela queima que antecede o corte da cana. Embora isto esteja sendo trabalhado, sobretudo em São Paulo, ainda é um problema nos estados que não avançaram em legislação ambiental (Ramão et al., 2007). Outro aspecto negativo diz respeito ao aumento da concentração da produção de cana, em decorrência do crescimento de grandes grupos. Este maior poder de mercado tem sido alvo dos órgãos de defesa da concorrência (Shikida et al., 2007).

Diante dessa relevância que a agroindústria canavieira assume na economia brasileira, a questão que se coloca é: Qual a importância da Usina Usaciga (Cidade Gaúcha-PR) para o desenvolvimento local? Assim, procura-se, neste trabalho, estimar o emprego básico e seu efeito multiplicador sobre o emprego total no município de Cidade Gaúcha-PR, ressaltando a contribuição da Usina Usaciga.

Nesse contexto, esta pesquisa vem colaborar para o conhecimento desse importante setor da economia brasileira e para os estudos do desenvolvimento local, podendo contribuir para elaboração de futuras políticas públicas que visem reduzir os entraves ao desenvolvimento de regiões brasileiras. 
Isto posto, este artigo está dividido em seis seções, incluindo esta introdução. Na seção dois são feitas breves notas sobre a Usina Usaciga, objeto maior deste estudo de caso. Na seção três apresenta-se o referencial teórico, cujo escopo é fundamentar conceitualmente a análise proposta. A quarta seção expõe a metodologia deste trabalho e a quinta, os resultados obtidos, assim como a discussão deste. Sumarizando, seguem as conclusões na sexta parte.

\section{Breves notas sobre a Usina Usaciga ${ }^{6}$}

Primeiramente, cumpre dizer que o município de Cidade Gaúcha, sede da Usina Usaciga, faz parte da mesorregião Noroeste Paranaense - que é composta por 61 municípios - e foi desmembrado dos municípios de Rondon e Cruzeiro do Oeste, tendo sua instalação ocorrido no dia 15 de novembro de 1961. Cidade Gaúcha possui 403,6 km² de área territorial e está distante $561,8 \mathrm{~km}$ de Curitiba [Instituto Paranaense de Desenvolvimento Econômico e Social (IPARDES, 2007a)]. Cidade Gaúcha possui 3.003 domicílios, sendo 2.354 localizados na zona urbana e 649, na zona rural [Instituto Brasileiro de Geografia e Estatística (IBGE, 2000)]. A população estimada atual do município é de 10.314 habitantes.

A Usina Usaciga foi constituída em 25 de julho de 1980, sendo sua denominação original Destilaria Cidade Gaúcha Ltda. Nessa época, a empresa produzia apenas álcool. Em 25 de julho de 1994, foi inaugurada a moderna fábrica de açúcar da Usaciga, pioneira na América Latina em sistema de Vácuo Contínuo e Automação Industrial. Tal acontecimento fez com que, naquele ano, a empresa fosse laureada pelo Jornal Cana com o título de empresa do ano em "Tecnologia Industrial", em âmbito nacional. A empresa passou então a denominar-se F.B. Açúcar e Álcool Ltda., com o nome Fantasia de "Usaciga".

A partir dessa data, a empresa investiu na melhoria do processo industrial, por meio da automação industrial e administrativa e, com a diversificação

6 Informações fornecidas pela empresa. 
da produção (álcool anidro, hidratado e açúcar), deu início a um plano de redução de custos industriais e, principalmente, agrícolas.

Em 2004, a empresa resolveu diversificar-se e investir em novos ramos de atividades, procurando tornar-se mais competitiva ao utilizar ao máximo as alternativas de transformação oferecidas pela cana-de-açúcar, como a co-geração de energia. A empresa passou então a usar o nome empresarial de Usaciga - Açúcar, Álcool e Energia Elétrica Ltda.

A Usaciga tem capacidade instalada atualmente para moer 8.500 toneladas/dia de cana-de-açúcar e produzir $15 \mathrm{mil} \mathrm{sacas/dia} \mathrm{de} \mathrm{açúcar} \mathrm{e}$ 250 mil litros/dia de álcool. A área colhida com cana pela empresa, na safra 2005/06, foi de 21.347,15 hectares, o que resultou na moagem de 1.298.270,75 toneladas de cana. Nessa mesma safra, produziu 2.402.600 sacas de açúcar e 30.166.796 litros de álcool. Do açúcar produzido, 99\% destinou-se à exportação.

Do total colhido com cana pela empresa, 8.841 hectares foram colhidos no município de Cidade Gaúcha. Isso representou 41,4\% da cana colhida pela empresa e $77,1 \%$ do total colhido em todas as lavouras no município, conforme informações do IBGE (2008).

As lavouras da Usaciga têm apresentado boa produtividade. Nas últimas três safras, a produtividade foi de 75,32 toneladas/hectare, acima, portanto, da média nacional, que é de 61 toneladas/hectare.

A Usaciga recolhe, no exercício fiscal, algo em torno de $\mathrm{R} \$ 8$ milhões em tributos. Nessa última safra, a empresa gerou 2.195 empregos diretos. Desse total de empregados, 272 trabalharam no setor industrial; 90, no setor administrativo; 38, no laboratório entomológico; 6 , na assistência social; e 1.789, no setor rural, que engloba cortadores de cana, técnicos agrícolas, motoristas, operadores de máquinas, entre outros. 


\section{Referencial teórico}

As teorias clássicas do desenvolvimento regional enfatizam a idéia da existência de uma força motriz de caráter exógeno capaz de influenciar as atividades econômicas de uma região por meio de encadeamentos. Entre essas teorias encontra-se a Teoria da Base de Exportação, que considera as exportações como a principal força desencadeadora do processo de desenvolvimento regional. Assim, a dinamicidade das atividades econômicas básicas incentiva o desenvolvimento de atividades complementares e o crescimento econômico. As atividades básicas vendem seus produtos em outras regiões, sendo a força motriz da economia, e as atividades complementares dão suporte às atividades básicas (Oliveira e Lima, 2003).

A Teoria da Base de Exportação é uma contribuição do economista norteamericano Douglass C. North. Para ele, o desenvolvimento regional iniciase pela exportação do principal produto produzido por uma região, ou seja, o produto que possui vantagem comparativa nos custos relativos de sua produção (North, 1977). Os primeiros produtos exportados por uma região, normalmente, são extrativos e, ou, agrícolas. A base de exportação compreende todos os produtos de exportação de uma região.

Segundo esse mesmo autor, além das atividades exportadoras, existem na região as atividades que atendem ao mercado local, as quais se desenvolvem onde reside a população consumidora. Entretanto, o papel vital na determinação do nível de renda da região é desempenhado por sua base de exportação.

Parte significativa das atividades secundárias e terciárias do tipo local desenvolve-se automaticamente na região, em função das altas rendas recebidas dos produtos de exportação. Uma base de exportação constituída por produtos agrícolas poderá estimular o desenvolvimento de uma indústria que utilize o produto do setor exportador como matériaprima, dadas as acentuadas vantagens de transferência do produto manufaturado sobre a matéria-prima bruta. Esse é o caso das indústrias 
de refinação de açúcar, moagem de farinha e madeireira. Essas indústrias passam a ser, então, parte da base de exportação.

A atividade de exportação pode estimular ainda o surgimento de atividades que prestem serviços para ela, como é o caso de fundições e fábricas de ferramentas para máquinas ou implementos especializados, por exemplo. A renda gerada pela atividade exportadora pode também atrair indústrias que produzam para o consumo local, algumas das quais podem desenvolver-se futuramente e também passar a fazer parte da base de exportação.

A idéia da base de exportação também está implícita nas teorias da economia urbana. De acordo com Singer (1987), as atividades existentes em uma economia urbana distinguem-se em atividades cuja produção se destina ao exterior e as em que a produção se destina ao consumo local. As exportações de uma economia urbana são constituídas de excedentes de sua produção para consumo interno.

São as atividades de exportação predominantes que definem a função econômica da cidade. Desse modo, algumas cidades têm caráter agrícola e outras, industrial e, ou, de serviços. Apesar de as indústrias serem vistas normalmente como atividades de caráter exportador, algumas são destinadas ao consumo local, como é o caso das padarias, da construção civil, das olarias, etc. As atividades de serviço são regularmente destinadas ao atendimento da população local, como o comércio varejista, os serviços de recreação, os serviços religiosos, entre outros. Entretanto, atividades hoje destinadas ao consumo local podem também desenvolver-se a ponto de tornarem-se exportadoras, com vistas em atrair consumidores de outras cidades, como no caso dos serviços de educação ou saúde.

O tamanho da cidade depende de sua capacidade de importar, que, em última instância, depende dos ganhos com exportação. As atividades do setor exógeno (atividades exportadoras) provocam um fluxo de renda para dentro da área urbana. O setor endógeno é responsável por satisfazer a demanda dos residentes da cidade que ganham renda do setor exógeno 
e gastam parte dela na comunidade local. As variações no nível total da atividade econômica da área urbana iniciam-se, portanto, pelo setor exógeno (Lane, 1977). A soma da renda (ou emprego) produzida nos dois setores determina o nível da renda total (ou emprego) da área urbana.

A elevação da renda em dada área urbana (devido ao crescimento de suas vendas para outras cidades) resulta num processo de novos gastos que produzem aumento múltiplo dessa renda (multiplicador da renda de Keynes). Dois fatores determinam a magnitude desse efeito multiplicador: a propensão marginal a consumir da área urbana e a propensão marginal a importar. A propensão marginal a consumir determinará qual é a parte da renda total que será gasta outra vez, a cada giro sucessivo de criação de renda. A propensão marginal a importar determina a parte do gasto total que se desvia da cidade a cada giro, não estando disponível para novos gastos.

Por um lado, a retração do mercado externo para produtos exportados pela área urbana provoca uma queda no nível de sua renda, o que prejudica as atividades que atendem ao consumo local. Por outro, uma elevação contínua no valor das exportações da cidade provoca aumento da imigração, o que gera um crescimento de sua população e estimula as atividades de consumo interno (Singer, 1987).

Desse modo, políticas que estimulem o desenvolvimento de atividades exportadoras presentes na cidade, ou que atraiam novas atividades exportadoras, tendem a dinamizar a economia urbana. $\mathrm{O}$ processo de dinamização da economia local pelo setor exportador ocorre graças aos efeitos de encadeamento e efeitos induzidos gerados por ele.

Os encadeamentos produtivos são ligações técnicas entre as atividades. Os efeitos de encadeamentos são "[...] impactos que as diferentes atividades exercem sobre as demais, quando aumentam sua produção" (Souza, 1999, p. 248). Conforme Hirschman (1973), esses encadeamentos produtivos podem ser de dois tipos: encadeamentos para trás (quando a atividade produtiva compra insumos); e encadeamentos para frente 
(quando a atividade produtiva vende insumos). Assim, parte do investimento em uma região resulta dos efeitos de encadeamento da atividade indutora, em função de suas compras e vendas de insumos.

O desenvolvimento do setor exportador de uma economia urbana - via crescimento das atividades já existentes ou instalação de novas atividades - tende a elevar os encadeamentos produtivos locais. O aumento da demanda de insumos para seu funcionamento beneficiará a região, que poderá produzir localmente boa parte desses insumos, seja por meio do sistema produtivo já existente, seja pela implantação de novas atividades produtoras desses insumos (encadeamentos para trás). Os produtos do setor exportador podem também servir de insumos para atividades da região ou, ainda, estimular a instalação na região de atividades que deles necessitem (encadeamentos para frente).

O crescimento da renda regional, em virtude do desenvolvimento do setor exportador e de sua influência em outras atividades, promoverá uma expansão da renda e dos mercados locais, estimulando o crescimento da produção local para o atendimento do consumo privado ou dos investimentos reais. Haverá aumento na demanda local de alimentos, vestuário, serviços médicos e de ensino, construção civil, entre outros, incentivando as atividades responsáveis por sua oferta. Esse é o efeito induzido, conforme Haddad (1999).

Entretanto, a condição para que o setor exportador possa gerar desenvolvimento na região vai depender da distribuição de renda e da origem do capital investido. Se a renda pessoal gerada pelo setor for insuficiente para produzir desconcentração da distribuição prevalecente, ou mesmo se ele reforçar a concentração, os efeitos induzidos para provocar a expansão do mercado interno regional serão menores. Da mesma maneira, se os capitais investidos no setor exportador forem oriundos de fora da região, os excedentes financeiros gerados não serão internalizados no novo ciclo produtivo da região. 
A Teoria da Base de Exportação, de North, tem ligação com a Abordagem do Produto Principal, de Harold Innis. Para Innis (1999) o comércio de algumas matérias-primas que eram exportadas para a Europa e Estados Unidos (peles, peixe, madeira, etc.) sustentou o desenvolvimento da indústria canadense. $\mathrm{O}$ foco de Innis está no estudo do crescimento engendrado pela produção e exportação de um produto principal. Como setor de destaque da economia, essa atividade estabelecerá o ritmo para as mudanças econômicas, políticas e sociais em determinada região.

\section{Metodologia}

Com alicerce na Teoria da Base de Exportação, procurou-se estimar o emprego básico e seu efeito multiplicador sobre o emprego total no município de Cidade Gaúcha-PR. A estimativa do multiplicador baseouse na metodologia proposta por Schickler (1972):

$\mathrm{E}=\mathrm{EB}+\mathrm{EN}$,

em que $E$ é o emprego total; $E B$, emprego básico; e $E N$, emprego nãobásico.

Admitindo-se a proporcionalidade entre o emprego não-básico e o emprego total, tem-se que:

$$
\begin{aligned}
& E N=\alpha E \quad(0<a<1) \\
& \mathrm{E}=\alpha \mathrm{E}+\mathrm{EB} \\
& E B=E-\alpha E \\
& E B=E(1-\alpha) \\
& E=\frac{1}{(1-\alpha)} \cdot E B
\end{aligned}
$$


$E=k \cdot E B$

em que

representa o multiplicador de emprego regional.

Na identificação do emprego básico de Cidade Gaúcha utilizou-se a metodologia sugerida por Cruz (1977):

$$
E B_{i}=S_{i}-\left[S_{t}\left(\frac{N_{i}}{N_{t}}\right)\right]
$$

em que $E B_{i}$ é emprego básico da atividade $i$ no município de Cidade Gaúcha; $S_{i}$, emprego na atividade $i$ no município de Cidade Gaúcha;

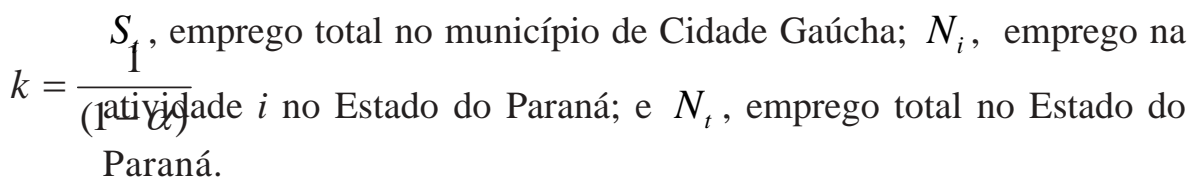
O quociente locacional $\left(Q L_{i j}\right)$ também tem auxiliado os pesquisadores a identificar atividades de exportação ou emprego básico, e seu uso, para esse fim, foi inclusive proposto por North (1977). O quociente locacional $\left(Q L_{i j}\right)$ de dado setor de atividade, conforme Haddad (1989), é obtido pela seguinte equação:

$$
Q L_{i j}=\frac{\left(E_{i j} / E_{i} .\right)}{\left(E_{. j} / E_{. .}\right)},
$$

em que $E_{i j}$ é número de empregados no setor $i$ no município de Cidade Gaúcha; $E_{._{j}}, \sum_{i} E_{i j}$, número total de empregados no município de 
Cidade Gaúcha; $E_{i} ., \sum_{j} E_{i j}$, número de empregados no setor $i$ no Paraná; $E . .=\sum_{i} \sum_{j} E_{i j}$, número total de empregados no Paraná.

Apesar de os outros autores já utilizarem a metodologia ora descrita para estimar o emprego básico e seu efeito multiplicador em municípios, microrregiões, mesorregiões, estados e macrorregiões brasileiras - como nos trabalhos de Piffer (1997), Pedralli (1999) e Piacenti et al. (2002) os resultados obtidos devem ser vistos com certa cautela, dadas as pressuposições da metodologia. A metodologia pressupõe que a produtividade do trabalho de dado setor de atividade da localidade em estudo seja semelhante à produtividade média do trabalho das localidades que compõem a região maior. Considera-se também que a propensão a consumir da população da localidade em estudo seja semelhante à propensão a consumir média das localidades que compõem a região maior.

Dado que um nível maior de desagregação da atividade econômica em setores produz uma estimativa mais realística do emprego básico e de seu efeito multiplicador, optou-se pelo uso dos dados de emprego da Relação Anual de Informações Sociais (RAIS), do Ministério do Trabalho e Emprego (MTE), cuja desagregação é de 25 setores. Além disso, os dados da RAIS têm a vantagem de serem mais atuais que os do Censo Demográfico, do IBGE. Os dados da RAIS, no entanto, têm o inconveniente de captarem apenas o emprego formal, cabendo aqui também pressupor que o percentual de emprego formal, em cada setor de atividade da localidade em estudo, seja semelhante ao percentual de emprego formal em cada setor de atividade na média das localidades que compõem a região maior. Os dados referentes à Usina Usaciga foram disponibilizados pela empresa.

Portanto, dadas as limitações metodológicas, este trabalho pretende encontrar uma estimativa do que poderia ser o emprego básico e seu efeito multiplicador no município de Cidade Gaúcha. 


\section{Resultados e discussão}

O número de pessoas empregadas no município de Cidade Gaúcha no ano de 2006, conforme dados da RAIS, foi de 2.915. De acordo com resultados da pesquisa (Tabela 1), estimou-se que 1.739 pessoas compunham o setor básico do município, enquanto 1.176 faziam parte do setor não-básico. Dos empregados no setor básico, 32 trabalhavam no setor indústria da borracha, fumo, couros, peles, produtos similares e indústria diversa; 179, no setor indústria de produtos alimentícios, de bebida e álcool etílico; e 1.528, no setor de agricultura, silvicultura, criação de animais, extração vegetal e pesca. Esses três setores apresentaram quociente locacional maior que a unidade - 2,46, 1,87 e 13,9, respectivamente - o que reforça a idéia de que eles produziram um excedente para exportação. 


\section{Tabela 1 - Quociente locacional, emprego básico e multiplicador de emprego do município de Cidade Gaúcha-PR}

\begin{tabular}{|c|c|c|c|c|}
\hline \multirow[t]{2}{*}{ Ramos de atividade } & \multicolumn{2}{|c|}{ Número de empregados } & \multirow{2}{*}{$\begin{array}{l}\text { Quociente } \\
\text { locacional }\end{array}$} & \multirow{2}{*}{$\begin{array}{l}\text { Emprego } \\
\text { básico }\end{array}$} \\
\hline & Cidade Gaúcha & Paraná & & \\
\hline Indústria de extração de minerais & 0 & 5.137 & 0,00 & - \\
\hline $\begin{array}{l}\text { Indústria de produtos minerais não- } \\
\text { metálicos }\end{array}$ & 9 & 20.569 & 0,34 & - \\
\hline Indústria metalúrgica & 39 & 34.847 & 0,86 & - \\
\hline Indústria mecânica & 0 & 29.347 & 0,00 & - \\
\hline $\begin{array}{l}\text { Indústria de materiais elétricos e de } \\
\text { comunicação }\end{array}$ & 0 & 15.022 & 0,00 & - \\
\hline Indústria de materiais de transporte & 8 & 31.261 & 0,20 & - \\
\hline Indústria da madeira e do mobiliário & 1 & 74.707 & 0,01 & - \\
\hline $\begin{array}{l}\text { Indústria do papel, papelão, editorial e } \\
\text { gráfica }\end{array}$ & 0 & 34.188 & 0,00 & - \\
\hline $\begin{array}{l}\text { Indústria da borracha, fumo, couros, peles, } \\
\text { produtos similares e indústria diversa }\end{array}$ & 54 & 16.965 & 2,46 & 32 \\
\hline $\begin{array}{l}\text { Indústria química, produtos farmacêuticos, } \\
\text { veterinários, perfumaria, sabões, velas e } \\
\text { matérias plásticas }\end{array}$ & 0 & 43.022 & 0,00 & - \\
\hline $\begin{array}{l}\text { Indústria têxtil, do vestuário e artefatos de } \\
\text { tecidos }\end{array}$ & 65 & 72.519 & 0,69 & - \\
\hline Indústria de calçados & 0 & 1.804 & 0,00 & - \\
\hline $\begin{array}{l}\text { Indústria de produtos alimentícios, de } \\
\text { bebida e álcool etílico }\end{array}$ & 385 & 158.879 & 1,87 & 179 \\
\hline Serviços industriais de utilidade pública & 0 & 23.554 & 0,00 & - \\
\hline Construção civil & 4 & 65.655 & 0,05 & - \\
\hline Comércio varejista & 156 & 384.380 & 0,31 & - \\
\hline Comércio atacadista & 3 & 67.704 & 0,03 & - \\
\hline $\begin{array}{l}\text { Instituições de crédito, seguro e de } \\
\text { capitalização } \\
\text { Administradoras de imóveis, valores } \\
\text { mobiliários, serviços técnicos }\end{array}$ & 16 & 40.672 & 0,30 & - \\
\hline profissionais, auxiliar atividade econômica & 17 & 176.727 & 0,07 & - \\
\hline Transporte e comunicações & 12 & 117.429 & 0,08 & - \\
\hline $\begin{array}{l}\text { Serviços de alojamento, alimentação, } \\
\text { reparo, manutenção, radiodifusão e } \\
\text { televisão }\end{array}$ & 56 & 194.057 & 0,22 & - \\
\hline $\begin{array}{l}\text { Serviços médicos, odontológicos e } \\
\text { veterinários }\end{array}$ & 21 & 70.217 & 0,23 & - \\
\hline Ensino & 30 & 77.711 & 0,30 & - \\
\hline Administração pública direta e indireta & 393 & 403.483 & 0,75 & - \\
\hline $\begin{array}{l}\text { Agricultura, silvicultura, criação de } \\
\text { animais, extração vegetal e pesca }\end{array}$ & 1.646 & 91.434 & 13,90 & 1.528 \\
\hline Total & 2.915 & 2.251 .290 & - & 1.739 \\
\hline Emprego não-básico: 1.176 & & & & \\
\hline Multiplicador de emprego: 1,6763 & & & & \\
\hline
\end{tabular}

Fonte: Resultado da pesquisa. 
Os demais setores de atividade do município apresentaram quociente locacional menor que a unidade, o que os caracteriza como atividades não-básicas, destinadas ao atendimento das demandas da população local e ao auxílio das atividades básicas. Esses setores compreendem pequenas indústrias - dos ramos de produtos minerais não-metálicos, metalurgia, materiais de transporte, madeira, mobiliário, têxtil e construção civil - e atividades de comércio, transporte e serviços em geral.

O multiplicador de empregos, estimado para Cidade Gaúcha, foi de aproximadamente 1,68 , o que indica que a renda gasta localmente por dez empregados do setor básico do município permite a manutenção de quase sete empregados no setor não-básico.

Os empregados da Usina Usaciga fazem parte de dois ramos de atividade que compõem o setor básico de Cidade Gaúcha: o setor indústria de produtos alimentícios, de bebida e álcool etílico e o de agricultura, silvicultura, criação de animais, extração vegetal e pesca. A empresa empregou, no ano em análise, 370 pessoas na fábrica e 560 pessoas ${ }^{7}$ no

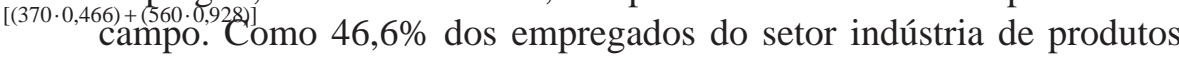
alimentícios, de bebida e álcool etílico e 92,8\% dos empregados do setor agricultura, silvicultura, criação de animais, extração vegetal e pesca faziam parte do setor básico de Cidade Gaúcha, estima-se que 691 seja o número de empregados da Usaciga que ajudaram a compor esse setor ${ }^{8}$.

Com isso, a participação do emprego básico da Usaciga no total do emprego básico de Cidade Gaúcha é de 39,7\%. Considerando-se o efeito multiplicador estimado em 1,68, a empresa é responsável, indiretamente, pela geração de mais 467 empregos no município, por meio da renda gasta localmente por seus empregados, oriunda das vendas da empresa para outras localidades no País e no mundo. Desse modo, a Usaciga é responsável, direta e indiretamente, pela geração de 1.158 postos de trabalho em Cidade Gaúcha.

Considerando-se apenas os empregados formais que trabalham nas lavouras de cana em Cidade Gaúcha. 
Pode-se dizer, portanto, que o município estaria em pior situação caso a Usina Usaciga não existisse, salvo se houvesse outra atividade econômica (ou outras) que a substituísse. Supondo ainda que o número de habitantes do município seja proporcional ao de empregados, na ausência da empresa, a população estimada do município (39,7\% menor, nesse caso) seria algo em torno de 6.215 habitantes, cerca de 4.099 habitantes a menos que os atuais 10.314 .

Cidade Gaúcha poderia estar hoje, então, em situação semelhante à de outros municípios da mesorregião Noroeste Paranaense, que enfrentaram perda significativa de população, principalmente nas décadas de 70 e 80 , diante do êxodo rural provocado pela decadência da cafeicultura no Estado. Dos 61 municípios da mesorregião, 33 apresentaram crescimento negativo de população nos anos 1980 a 2000, conforme dados dos Censos Demográficos (IBGE, 1980 e 2000). Desses, 9 municípios tiveram perda de população superior a 50\%, nesse mesmo período.

No período 1970-1980 (anterior ao início das atividades da Usina Usaciga), Cidade Gaúcha apresentava perda de população rural (60,3\%) mais expressiva que a perda média dos municípios que compõem a mesorregião Noroeste $(45,6 \%)$, além de um crescimento de população urbana $(40,8 \%)$ inferior ao da média da mesorregião $(42,5 \%)$, resultando em maior perda de população total (36,7\% em Cidade Gaúcha, contra $22,4 \%$ na média da mesorregião), conforme informações apresentadas na Tabela 2. 
Tabela 2 - População residente urbano, rural e total do município de Cidade Gaúcha-PR e da mesorregião Noroeste Paranaense $-1970,1980,1991$ e 2000

Fonte: Elaborado pelos autores a partir dos dados do $\operatorname{IBGE}(1970,1980,1991 \mathrm{e}$ 2000).

Ao considerar o período posterior ao início das atividades da Usaciga (1980-2000), verifica-se que o crescimento da população urbana do município $(79,6 \%)$ foi suficiente para compensar a perda de população rural no mesmo período $(53,5 \%)$ e fazer com que o município ganhasse $15,5 \%$ de população total. A mesorregião Norpeçąe Parantąąnse, no

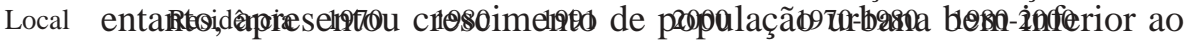

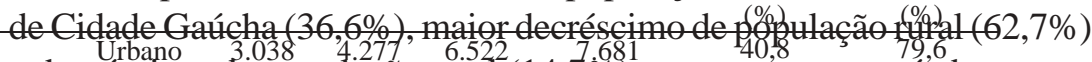

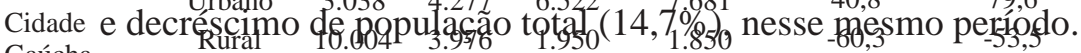

Gaúcha Total $\quad \begin{array}{llll}13.042 & 8.253 & 8.472 & 9.531\end{array}$ $-36,7$ 15,5

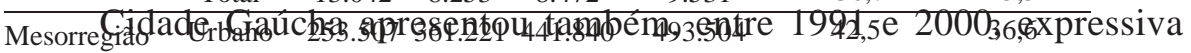

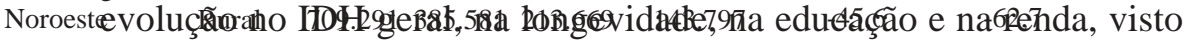

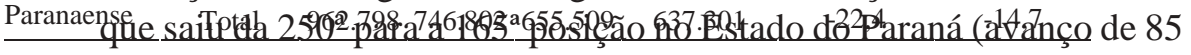
posições). Não obstante, esse avanço em relação ao IDH ocorreu também no Paraná e, nesse cotejo, embora a evolução de Cidade Gaúcha tenha sido clara, seus indicadores ainda permanecem abaixo da média paranaense (Tabela 3). 
Tabela 3 - Índice de desenvolvimento humano (IDH) do município de Cidade Gaúcha e do Estado do Paraná - 1991 e 2000

\begin{tabular}{lcccccccccc}
\hline & \multicolumn{9}{c}{ I991 } & \multicolumn{1}{c}{2000} \\
\cline { 2 - 11 } & $\begin{array}{c}\text { IDH } \\
\text { Geral }\end{array}$ & $\begin{array}{c}\text { IDH } \\
\text { Longevidade }\end{array}$ & $\begin{array}{c}\text { IDH } \\
\text { Educação }\end{array}$ & $\begin{array}{c}\text { IDH } \\
\text { Renda }\end{array}$ & Ranking & $\begin{array}{c}\text { IDH } \\
\text { Geral }\end{array}$ & $\begin{array}{c}\text { IDH } \\
\text { Longevidade }\end{array}$ & $\begin{array}{c}\text { IDH } \\
\text { Educação }\end{array}$ & $\begin{array}{c}\text { IDH } \\
\text { Renda }\end{array}$ & Ranking \\
\hline PR & 0,711 & 0,678 & 0,778 & 0,678 & - & 0,787 & 0,747 & 0,879 & 0,736 & - \\
$\begin{array}{l}\text { Cidade } \\
\text { Gaúcha }\end{array}$ & 0,645 & 0,591 & 0,738 & 0,607 & 250 & 0,749 & 0,712 & 0,858 & 0,676 & 165 \\
\hline
\end{tabular}

Fonte: Ipardes (2007b).

Nota: o índice 0,500 é considerado um ponto crítico: abaixo deste configura-se situação intolerável; de 0,500 a 0,799 tem-se um estágio médio de desenvolvimento; de 0,800 a 1, a situação é favorável ao desenvolvimento.

O fato de a média paranaense do IDH ser maior que a da Cidade Gaúcha pode incitar algumas críticas ao tom mais de crescimento do que de desenvolvimento proporcionado pelo sinergismo da agroindústria canavieira. Com efeito, para Ferreira Júnior e Hespanhol (2006), nesse setor o que se busca é maior eficiência, baseada na produção em grande escala e incorporadora de modernas tecnologias. Outros elementos, como a melhor distribuição de renda e riqueza ainda não estão sendo alcançados.

\section{Conclusões}

Este trabalho objetivou estimar o emprego básico e seu efeito multiplicador sobre o emprego total no município de Cidade Gaúcha-PR, ressaltando a contribuição da Usina Usaciga.

Como corolário, estimou-se que 1.739 pessoas compõem o setor básico do município, enquanto 1.176 pessoas fazem parte do setor não-básico. Dos empregados no setor básico, 32 trabalham no setor indústria de borracha, fumo, couros, peles, produtos similares e indústria diversa; 179, no setor indústria de produtos alimentícios, de bebida e álcool etílico; e 1.528 , no setor de agricultura, silvicultura, criação de animais, extração vegetal e pesca. 
O multiplicador de empregos, estimado para Cidade Gaúcha, foi de aproximadamente 1,68 , o que indica que a renda gasta localmente por dez empregados do setor básico do município permite a manutenção de quase sete empregados no setor não-básico.

Estimou-se em 691 o número de empregados da Usaciga, os quais ajudam a compor o setor básico de Cidade Gaúcha (39,7\% desse setor). Desse modo, a Usaciga é responsável, direta e indiretamente, pela geração de 1.158 postos de trabalho nessa localidade.

Cidade Gaúcha passou de uma situação inferior - antes do início das atividades da Usaciga, este município apresentava menor crescimento urbano, maior êxodo rural e maior perda de população total que a mesorregião Noroeste Paranaense - para uma situação mais favorável, com perda menos acentuada de população rural e crescimento urbano mais acelerado que a média dos municípios integrantes da mesorregião.

De 1991 a 2000, houve boa evolução no IDH geral, na longevidade, na educação e na renda do município de Cidade Gaúcha, que saiu da 250ª para a $165^{a}$ posição no Estado do Paraná (avanço de 85 posições). Logo, pode-se inferir que Cidade Gaúcha caminha de um estágio médio de desenvolvimento para o patamar mais avançado (IDH geral de 0,645, em 1991, para 0,749, em 2000). Esse fato não pode ser creditado exclusivamente à dinâmica econômica que a Usina Usaciga tem proporcionado à cidade, mas a sua participação, observados os indicadores já salientados nesta pesquisa, contribuiu para maior desenvoltura local.

Por último, mas não menos importante, sugere-se que mais trabalhos possam ser implementados para examinar a importância de determinada atividade econômica (neste caso, a agroindústria canavieira) para o desenvolvimento e crescimento local. 


\section{Referências}

ASSOCIAÇÃO DE PRODUTORES DE ÁLCOOL E AÇÚCAR DO ESTADO DO PARANÁ (ALCOPAR). Disponível em: <http:// www.alcopar.org.br>. Acesso em: 27 mar. 2007.

CRUZ, A. R. M. Importância do turismo para a economia do Estado do Paraná: estudo dos impactos dos multiplicadores de renda e emprego nas cidades de Curitiba e Foz do Iguaçu. 1977. Monografia. Universidade Federal do Paraná, Curitiba, 1977.

FERREIRA JÚNIOR, A. C.; HESPANHOL, A. N. Os efeitos das políticas voltadas ao setor sucroalcooleiro no Estado de São Paulo. Geografia em Atos, v.1, n. 6, p.1-9, dez., 2006.

GUERRA, N. A. M. O Pró-álcool e as transformações no espaço agrícola do Paraná. Economia em Revista, v. 4, n. 2, p. 81-95, 1995.

HADDAD, P. R. A concepção de desenvolvimento regional. In: HADDAD, P. R. et al. (Org.). A competitividade do agronegócio e o desenvolvimento regional no Brasil: estudo de cluster. Brasília: CNPq/Embrapa, 1999. p. 9-22.

HADDAD, P. R. Medidas de localização e de especialização. In: HADDAD, P. R. (Org.). Economia Regional: teorias e métodos de análise. Fortaleza, BNB/ETENE, 1989. p. 225-248 (Estudos Econômico e Sociais, 36).

HIRSCHMAN, A. O. La estratégia del desarrollo económico. México: Fondo de Cultura Económico, 1973.

INNIS, H. Changing concepts of time. Toronto. Toronto University Press. 1952. $176 \mathrm{p}$.

INSTITUTO BRASILEIRO DE GEOGRAFIA E ESTATÍSTICA 
(IBGE). Censo Demográfico 1970. Rio de Janeiro: IBGE, 1970.

. Censo Demográfico 1980. Rio de Janeiro: IBGE, 1980.

. Censo Demográfico 1991. Rio de Janeiro: IBGE, 1991.

. Censo Demográfico 2000. Rio de Janeiro: IBGE, 2000.

. Produção Agrícola Municipal de 2006. Rio de Janeiro.

Disponível em: <http://www.ibge.gov.br>. Acesso em: 05 jan. 2008.

INSTITUTO PARANAENSE DE DESENVOLVIMENTO ECONÔMICO E SOCIAL Cadernos municipais: caderno estatístico, município de Cidade Gaúcha. Curitiba, 2007a. Disponível em: <http://www.ipardes.gov.br>. Acesso em: 26 mar. 2007.

Índices e indicadores. Curitiba, 2007b. Disponível em: <http:/ /www.ipardes.gov.br>. Acesso em: 26 mar. 2007.

KAEFER, G. T.; SHIKIDA, P. F. A. The genesis of sugar cane industry in Paraná State and its recent development. In.: CONGRESSO BRASILEIRO DE ECONOMIA E SOCIOLOGIA RURAL, 38, 2000, Rio de Janeiro. Anais. Brasília: SOBER, 2000.

LANE, T. O multiplicador da base urbana: avaliação de sua situação atual. In: SCHWARTZMAN, J. (Org.). Economia regional: textos escolhidos. Belo Horizonte: Cedeplar, 1977. p. 241-253.

MACEDO, I. C. Geração de qualidade de empregos. 2007. Disponível em: <http://www.portalunica.com.br>. Acesso em: 07 mar. 2007.

NORTH, D. C. Teoria da localização e crescimento econômico regional. In: SCHWARTZMAN, J. (Org.). Economia regional: textos escolhidos. Belo Horizonte: Cedeplar, 1977. p. 291-314. 
OLIVEIRA, G. B. de; LIMA, J. E. de S. Elementos endógenos do desenvolvimento regional: considerações sobre o papel da sociedade local no processo de desenvolvimento sustentável. Revista da FAE, Curitiba, v. 6, n. 2, p. 29-37, maio/dez. 2003.

PEDRALLI, V. R. O crescimento das mesorregiões do Paraná em comparação com a economia nacional. 1999. 50 f. Monografia (Graduação em Ciências Econômicas) - Universidade Estadual do Oeste do Paraná, Toledo, 1999.

PIACENTI, C. A.; STAMM, C.; LIMA, J. F. de; PIFFER, M. Adinâmica da base de exportação das regiões do Brasil. Estudos \& Debate, Lajeado, v. 9, n. 2, p. 95-109, 2002.

PIFFER, M. A dinâmica do Oeste Paranaense: sua inserção na economia nacional. 1997. 169 f. Dissertação (Mestrado em Desenvolvimento Econômico) - Universidade Federal do Paraná, Curitiba, 1997.

RAMÃO, F. P.; SCHNEIDER, I. E.; SHIKIDA, P. F. A. Padrão tecnológico no corte de cana-de-açúcar: um estudo de caso no Estado do Paraná. Revista de Economia Agrícola, São Paulo (SP), v.54, n.1, p.21-32, jan./jun., 2007.

SCHICKLER, S. A teoria da base econômica regional: aspectos conceituais e testes empíricos. In: HADDAD, P. R. Planejamento regional: métodos e aplicações ao caso brasileiro. Rio de Janeiro: IPE/ INPE, 1972.

SHIKIDA, P. F. A. A evolução diferenciada da agroindústria canavieira no Brasil de 1975 a 1995. Cascavel: Edunioeste, 1998. $149 \mathrm{p}$.

SHIKIDA, P. F. A.; VIAN, C. E. de F.; LIMA, R. A. de S.; SILVA, J. R. da; DAHMER, V. de S. Mudança organizacional da agroindústria canavieira paranaense pós-desregulamentação setorial. In: ENCONTRO 
BRASILEIRO DE ESTUDOS REGIONAIS, 5, Recife, 2007. Anais. Recife: ENABER, 2007.

SILVA, A. M. A. da; PONTILI, R. M. O papel da Usina de Açúcar e Álcool Goioerê Ltda. como indústria motriz para o município de Moreira Sales - Paraná. In: ENCONTRO DE ECONOMIA PARANAENSE, 4., 2005, Toledo. Anais. Toledo: Unioeste, 2005.

SINGER, P. Economia política da urbanização. 11. ed. São Paulo: Brasiliense, 1987.152 p.

SOUZA, N. J. Desenvolvimento econômico. 4. ed. São Paulo: Atlas, 1999. $415 \mathrm{p}$.

Abstract - The objective of this study was to estimate the basic employment and its multiplier effect on total employment in the of the Cidade Gaúcha municipality, emphasizing the contribution of Usaciga plant. According to the results, 1,739 people make up the basic employment of the municipality, while 1,176 people are part of the non-basic employment. The Usaciga is responsible for $39.7 \%$ of the basic employment of Cidade Gaúcha. The dynamics of population growth of Cidade Gaúcha has changed from the 1980, when the Usaciga started its activities. There was also positive evolution in terms of Human Development Index (HDI) in this municipality.

Keywords: sugar cane agroindustry, local development, employment multiplier. 
REVISTA DE ECONOMIA E AGRONEGÓCIO, VOL.6, $N^{\circ} 1$ 